\title{
IDOSOS PROVEDORES: A IMPORTÂNCIA DOS RECURSOS DA APOSENTADORIA PARA AS FAMÍLIAS BRASILEIRAS
}

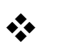 \\ Silvia Virginia Coutinho Areosa \\ Universidade de Santa Cruz do Sul - UNISC - Brasil
}

Resumo

Este trabalho traz como recorte o "idoso provedor" que através do benefício da previdência social (aposentadoria e pensões) é o mantenedor de sua família, o "chefe". Nesta investigação foram entrevistadas 34 pessoas com mais de 60 anos, provedores do núcleo familiar com o recurso de sua aposentadoria e/ou pensão. Encontrou-se na amostra 59\% de aposentados e $57,3 \%$ destes relatam viver somente dos recursos da aposentadoria, 22,4\% dos pesquisados vivem de pensão e 14,2 \% apontam os alugueis como forma de se manter. Os idosos se reconhecem como provedores dos seus núcleos familiares e, isto está lhes causando preocupação e restrição da liberdade, porém também se sentem importantes e valorizados.

Palavras- chave: Idoso provedor. Aposentadoria. Renda familiar.

\section{Introdução}

O IBGE, nos últimos anos, em seus dados estatísticos, mostra que a taxa média de crescimento da população (taxa de natalidade) vem apontando uma tendência regular ao declínio na média de filhos por mulher. Em face dessas quedas nos índices de natalidade em nosso país, a previsão estatística para o ano de 2025 era de dois filhos por mulher, o que já foi atingido no ano de 2007 com índice de natalidade de 1,95, sendo que já se encontra como mera reposição das gerações (IBGE, 2007). O Brasil está tornando-se, assim, um país com mais idosos e menos jovens, o que pode ser observado nas mudanças da pirâmide etária, por conta da combinação no que tange à redução das taxas de mortalidade e de natalidade.

A longevidade tem sido uma das maiores conquistas das últimas décadas em nosso país. Com o aumento da esperança de vida surgiram consequências inesperadas para o Brasil, trazendo a tona, novas questões e demandas por parte da população idosa relacionadas com a saúde, a moradia, a previdência social, o trabalho, a dependência funcional, o declínio cognitivo, os cuidados de longa duração, entre outros. 
O prolongamento da vida até idades mais avançadas faz com que as famílias convivam entre diferentes gerações, este modelo de família se caracteriza por um maior peso nas relações de reciprocidade entre os seus membros (TUR; OLIVARES, 2005).

Para Zimerman (2000), quando envelhecemos vemos a família se modificando, em especial a posição de cada membro dentro dela. Para a pessoa idosa, a família passa a ser: os filhos, netos, bisnetos e outros parentes, de idade inferior à dele e, muitas vezes, a relação de dependência se torna diferente. Segundo dados do IBGE e das PNADs é crescente o número de famílias que possuem idosos como chefes e filhos morando junto. Esta proporção passou de 32\% em 1986 para 36\% em 1996, 41\% em 2000 e, 45\% em 2007, o que pode ser efeito da situação econômica atual, que faz com que os filhos saiam mais tarde de casa ou que retornem após o casamento, estando separados ou não. É importante também observar que os idosos ocupam significativamente a posição de chefia nestes arranjos. O tipo mais comum é aquele no qual o idoso mora com seus filhos, 44,5\%, no conjunto do país (IBGE, 2007).

Os estudos do IPEA apontam que a renda média dos maiores de 60 anos é maior que a dos jovens (aqueles com menos de 30 anos) e que a proporção de chefes idosos que moram em casa própria é mais elevada do que a dos jovens, reforçando a hipótese de que os idosos que recebem o benefício da aposentadoria ou pensão estão em melhor situação econômica que os jovens, os quais estão conseguindo se inserir cada vez mais tardiamente no mercado de trabalho e, às vezes, inclusive nem conseguem (CAMARANO, 1999, 2001).

Com a ampliação do desemprego e o incremento de várias formas de precarização da mão-de-obra, as famílias acabam dependendo mais de seus idosos, que passam a contribuir com os benefícios previdenciários ou com a renda do trabalho, na renda familiar. Tal situação é corroborada pelos dados da Pesquisa de Emprego e Desemprego (PED), os quais ainda revelam que a contribuição da renda do idoso na renda familiar é tanto maior quanto menor é o nível de renda desse grupo. Ou seja, a proporção da renda do chefe idoso na renda familiar é de cerca de $70 \%$ quando ele recebe menos de três salários mínimos, enquanto para aquele que recebe acima de 10 salários mínimos a sua contribuição para a renda familiar é em torno de $40 \%$ (KRELING, 2002).

As aposentadorias desempenham um papel muito importante na renda dos idosos e essa importância cresce com a idade. Pode-se concluir que o grau de dependência dos indivíduos idosos é, em boa parte, determinado pela provisão de rendas por parte do Estado. Como uma parcela importante da renda familiar depende da renda do idoso, sugere-se que quando se reduzem ou se aumentam benefícios previdenciários, o Estado não está simplesmente atingindo indivíduos, mas uma fração razoável dos rendimentos de famílias Barbarói, Santa Cruz do Sul, n.45, p.<173-184>,jul./dez. 2015 
inteiras. Isso é importante de ser notado porque, como consequência, o perfil do sistema previdenciário construído hoje influirá na distribuição futura da renda das famílias.

Diante deste cenário, e tendo como pressupostos que a política de seguridade social é uma forma de redistribuição de renda, que as relações familiares são atravessadas pela questão econômica o que esta pesquisa buscou investigar foi como os idosos, a partir da condição de chefes de família, são reconhecidos neste papel?

\section{Metodologia}

Utilizou-se como recorte para esta pesquisa as famílias de idosos de diferentes classes sociais, que fazem uso dos serviços da Universidade de Santa Cruz do Sul - UNISC, campus de Santa Cruz do Sul, sendo um estudo predominantemente qualitativo, embora sejam utilizados alguns procedimentos quantitativos. Em relação à coleta de dados, após aprovação do Comitê de Ética em Pesquisa da UNISC (Of. N²70/05), iniciaram-se os contatos telefônicos com os idosos, previamente selecionados, para marcar os encontros.

Foram incluídos na amostra qualitativa, pelos critérios previamente estabelecidos (ser autônomo e independente, ter mais de 60 anos, viver de aposentadoria ou pensão, ser chefe de família) todos os idosos que estavam nessas condições. Dessa forma, o número se reduziu espontaneamente para 38 idosos, porém apenas 34 entrevistas foram validadas para análise.

A análise das entrevistas deste estudo foi feita através da construção e definição de grandes categorias de análise. Conforme Bardin (2004, p. 9), esse procedimento definido como análise de conteúdo, é "um conjunto de instrumentos metodológicos que se aplicam a 'discursos' (conteúdos e continentes). Dessa forma, a análise de conteúdo instrumentaliza a interpretação não somente dos dados em si, mas possibilita a inferência e a generalização entre as diferentes perspectivas e enunciados dos entrevistados, indivíduos que, apesar de uma série de características que os aproximam, são únicos na expressão de sua vida, vivências e experiências.

Os dados quantitativos da amostra foram organizados em tabelas e gráficos com o auxílio do software StatisticalPackage for the Social Sciences (SPSS) versão 13.0, para melhor visualização e análise. 


\section{Resultados e discussão}

Ao identificar quem são os participantes da pesquisa verifica-se que dentre os 34 sujeitos que concordaram após contato telefônico, em participar deste estudo, tem-se 21 mulheres e 13 homens, com idades que variaram entre 61 e 86 anos, revelando que existem muitos provedores na faixa etária considerada como idosos. Observa-se inclusive que alguns idosos longevos ainda se encontram nesta posição, como se pode verificar na tabela abaixo.

Tabela 1 - Amostra de idosos representada por idade e sexo

\begin{tabular}{|c|c|c|c|c|c|c|}
\hline \multirow{2}{*}{ Idade } & \multicolumn{4}{|l|}{ Sexo } & \multirow{2}{*}{\multicolumn{2}{|c|}{$\begin{array}{l}\mathrm{N}^{\mathrm{o}} \mathrm{de} \\
\text { respostas }\end{array}$}} \\
\hline & Masculino & $\%$ & Feminino & $\%$ & & \\
\hline $61-65$ & 5 & 38,7 & 7 & 33,5 & 12 & 35,5 \\
\hline $66-70$ & 4 & 30,7 & 6 & 28,5 & 10 & 29,4 \\
\hline $71-75$ & 2 & 15,3 & 5 & 23,8 & 7 & 20,5 \\
\hline $76-80$ & 2 & 15,3 & 2 & 9,5 & 4 & 11,7 \\
\hline $\begin{array}{l}\text { Acima de } \\
80\end{array}$ & 0 & 0 & 1 & 4,7 & 1 & 2,9 \\
\hline Total & 13 & 100 & 21 & 100 & 34 & 100 \\
\hline
\end{tabular}

FONTE: Pesquisa de campo

Como se pode constatar na tabela 1 , há um percentual maior de mulheres do que de homens em todas as faixas etárias e, a partir dos 80 anos só encontrou-se uma mulher na amostra de chefes de família. A amostra apresenta-se majoritariamente feminina, pois esta foi selecionada dentro dos serviços da Universidade e sabe-se pela literatura que as mulheres participam mais das atividades sociais quando nesta faixa etária.

A feminilização da velhice é um processo bastante estudado dentro da Gerontologia Social e indica que a proporção de mulheres é bem superior ao número de homens, fenômeno este que se apresenta em nível mundial. Este dado aponta a necessidade de pensar as condições de vida destas idosas na perspectiva de um envelhecimento saudável e satisfatório, como também pensar na saúde dos homens, para que estes alcancem uma expectativa de vida maior. Desta forma, torna-se fundamental a efetivação das políticas públicas de saúde para os idosos, já que nesta fase encontram-se mais vulneráveis e podem apresentar situações de 
dependência, necessitando assim de serviços e ações de saúde que dêem conta de um cuidado integral (LIMA; BUENO, 2009).

Cabe observar que as famílias chefiadas por mulheres têm crescido nas últimas décadas. No Brasil, em 2005, era estimada em 30,6\% e em 2006 este grupo representava 31\% (IBGE, 2006). O critério utilizado pela população recenseada, de maneira geral, para definir o responsável pelo domicílio é quem tem a maior remuneração. As famílias chefiadas por mulheres correspondem a 18,5 milhões de famílias. Uma em cada quatro famílias brasileiras é chefiada por mulheres. Nesse universo, a maioria das mulheres responsáveis pelo domicílio está em situação monoparental.

Outro aspecto importante a ser analisado refere-se à escolaridade dos sujeitos pesquisados, característica que é própria de uma faixa etária onde o acesso à Educação era mais dificultado tanto pelo acesso quanto pela própria valorização que era dada ao mesmo.

O nível de escolaridade também foi estudado em pesquisa realizada por Anderson (1998) que encontrou baixo percentual de estudo entre os idosos: "mais de 80\% dos idosos tinha cursado, no máximo, até a quarta série, o que correspondia, à época, ao primário completo. No Nordeste, de cada dez idosos, sete nunca concluíram sequer um ano de estudo"( p.2).

Esse baixo nível de escolaridade deve ser considerado quando do planejamento de programas e ações, tanto no nível coletivo quanto no individual, pensando em garantir o direito dos idosos a cidadania.

Pode-se verificar através da tabela 2 , que entre os sujeitos do sexo masculino há uma distribuição mais uniforme entre os níveis de escolaridade, não se sobressaindo nenhum nível, porém, entre os sujeitos do sexo feminino há uma concentração maior de mulheres com ensino fundamental incompleto, podendo isso ser reflexo de questões culturais da época em que estas mulheres se encontravam em idade escolar, como o fato de ser mais importante preparar-se para o casamento do que estudar.

Tabela 2 - Relação entre a escolaridade e o sexo dos idosos entrevistados

\begin{tabular}{|c|c|c|c|c|c|c|}
\hline \multirow{2}{*}{ Escolaridade } & \multicolumn{4}{|l|}{ Sexo } & \multirow{2}{*}{\multicolumn{2}{|c|}{$\begin{array}{l}\mathrm{N}^{\mathrm{o}} \mathrm{de} \% \\
\text { respostas }\end{array}$}} \\
\hline & Masculino & $\%$ & Fer & $\%$ & & \\
\hline $\begin{array}{l}\text { Ensino fundamental } \\
\text { incompleto }\end{array}$ & 3 & 23,5 & 12 & 57,4 & 15 & 44,4 \\
\hline Ensino fundamental & 2 & 15,3 & 4 & 19,0 & 6 & 17,6 \\
\hline
\end{tabular}




\begin{tabular}{|c|c|c|c|c|c|c|}
\hline completo & & & & & & \\
\hline $\begin{array}{l}\text { Ensino médio } \\
\text { incompleto }\end{array}$ & 1 & 7,6 & 2 & 9,5 & 3 & 8,8 \\
\hline $\begin{array}{l}\text { Ensino médio } \\
\text { completo }\end{array}$ & 2 & 15,3 & 1 & 4,7 & 3 & 8,8 \\
\hline Ensino técnico & 2 & 15,3 & 1 & 4,7 & 3 & 8,8 \\
\hline $\begin{array}{l}\text { Analfabeto/ } 1^{\mathrm{a}} \text { série } \\
\text { incompleto }\end{array}$ & 2 & 15,3 & 0 & 0 & 2 & 5,8 \\
\hline $\begin{array}{l}\text { Ensino superior } \\
\text { completo }\end{array}$ & 1 & 7,6 & 0 & 0 & 1 & 2,9 \\
\hline Pós-graduação & 0 & 0 & 1 & 4,7 & 1 & 2,9 \\
\hline Total & 13 & 100 & 21 & 100 & 34 & 100 \\
\hline
\end{tabular}

FONTE: Pesquisa de campo

$\mathrm{Na}$ pesquisa em análise as mulheres, em sua maioria, tornaram-se chefe de família após a aposentadoria ou a viuvez/pensão, não tendo, portanto se dedicado tanto aos estudos e à profissionalização. $\mathrm{O}$ fato de serem provedores, apesar da baixa escolaridade (43\% possuem ensino fundamental incompleto), muitas vezes, é avaliado como algo positivo, alguém que apesar de não ter tido estudo, conseguiu vencer na vida, comprar casa e formar família. Podese verificar que entre os sujeitos do sexo masculino há uma distribuição mais uniforme entre os níveis de escolaridade, porém, entre os sujeitos do sexo feminino há uma concentração maior de mulheres com ensino fundamental incompleto, podendo ser reflexo de questões culturais da época em que estas mulheres se encontravam em idade escolar, como o fato de ser mais importante preparar-se para o casamento do que estudar.

Aqui, são estudadas duas variáveis, sexo e estado civil, estabelecendo-se uma relação entre ambas, com o intuito de conhecer melhor quem são os participantes deste estudo. Conforme a tabela 03, a grande maioria dos homens é casado e,entre as mulheres, existem diferentes situações, porém a maioria é viúva.

Tabela 3 - Relação entre estado civil e o sexo da amostra

\begin{tabular}{|c|c|c|c|}
\hline \multirow{2}{*}{ Estado civil } & \multicolumn{2}{|l|}{ Sexo } & \multirow{2}{*}{$\begin{array}{l}\mathrm{N}^{\circ} \quad \mathrm{de} \\
\text { respostas }\end{array}$} \\
\hline & Masculino \% & Feminino $\%$ & \\
\hline Casado & 92,4 & 19,2 & 47,4 \\
\hline
\end{tabular}




\begin{tabular}{l|llll|ll} 
Viúvo & 0 & 0 & 12 & 57,1 & 12 & 35,2 \\
Divorciado & 0 & 0 & 2 & 9,5 & 2 & 5,8 \\
Separado & 0 & 0 & 2 & 9,5 & 2 & 5,8 \\
Solteiro & 0 & 0 & 1 & 4,7 & 1 & 2,9 \\
União estável & 1 & 7,6 & 0 & 0 & 1 & 2,9 \\
\hline Total & 13 & 100 & 21 & 100 & 34 & 100 \\
\hline
\end{tabular}

FONTE: Pesquisa de campo

E isto é o que se verifica nesta amostra de chefes de família com $100 \%$ dos homens em situação marital e apenas 19\% das mulheres nesta situação, sendo $57 \%$ de viúvas e $19 \%$ que foram casadas e hoje se encontram separadas. Ainda segundo o IBGE (2007), apesar de nascerem mais homens no país, são as mulheres que vivem mais e, portanto, permanecem um maior tempo viúvas. Para Neri e Debert (2004) o maior número de mulheres idosas continuará prevalecendo e será tanto maior quanto mais avançada for a idade. A grande maioria são viúvas, morando na casa dos filhos, ou chefiando famílias (26,7\% em 2007 segundo os Indicadores Sociais do IBGE).

Aposentadorias e pensões, no ano de 2006, segundo a PNAD, beneficiaram um grande número de pessoas idosas. No grupo de 60 anos ou mais, o percentual de beneficiados era de $76,6 \%$ aumentando para $84,6 \%$ quando se refere ao conjunto dos idosos de 65 anos ou mais. O Sul é a região com maior cobertura previdenciária, superando a média nacional, com 88,9\% (IBGE, 2007).

\section{Tabela 4 - Fontes de renda atual dos idosos entrevistados}

\begin{tabular}{lll}
\hline FONTES DE RENDA & Frequência & $\%$ \\
ATUAL & & \\
\hline Aposentadoria & 28 & 57,3 \\
Pensão & 11 & 22,4 \\
Aluguéis & 7 & 14,2 \\
Outros & 3 & 6,1 \\
\hline Total & 49 & 100 \\
\hline
\end{tabular}

FONTE: pesquisa de campo 
Através das respostas dos entrevistados percebeu-se que 59\% da amostra desta pesquisa são aposentados e 57,3 \% dizem que vivem somente da aposentadoria, 22,4\% declaram viver de pensão e ainda 14,2 \% apontam os aluguéis como forma de se manter, como se pode verificar na tabela 4 . Observa-se também, que 15 pessoas apontam mais de uma fonte de renda para se manter é o caso, por exemplo, das viúvas que possuem pensão e também são aposentadas.

No Brasil e no Rio Grande do Sul a aposentadoria cada vez mais tem se tornado a única fonte de renda de milhares de famílias. Dentre os sujeitos pesquisados, a maioria possui duas ou três pessoas que dependem da sua renda (32,4 e 35,3\%, respectivamente). Aqui se percebe a importância do sistema previdenciário, possibilitando que estas pessoas, após uma jornada longa de trabalho e contribuição, possam se aposentar e usufruir desse benefício e, no caso das mulheres, também de pensão, além de contribuírem com a manutenção de milhares de famílias, como apontam Camarano e Pasinato (2002).

Existe também uma dimensão importante da aposentadoria que se refere ao imaginário, as representações sociais que as pessoas possuem sobre o estar aposentado, a partir dos estudos de França e Vaughan (2008) com executivos, verificou-se que a aposentadoria representa aspectos positivos como: a liberdade por não ter que trabalhar, mais tempo para os relacionamentos, um novo começo e mais tempo para atividades culturais e de lazer. Porém também representam aspectos negativos como: os aspectos emocionais do trabalho, os aspectos tangíveis do trabalho, os relacionamentos feitos no trabalho e a diminuição dos salários.

Tabela 5 - Quem depende da renda do idoso?

\begin{tabular}{lll}
\hline QUEM DEPENDE & DA & $\%$ \\
SUA RENDA & $\mathrm{N}^{\mathrm{o}}$ de respostas & $\%$ \\
\hline Idoso e filho (s) & 16 & 35,8 \\
Idoso e outros parentes & 13 & 28,8 \\
Idoso, cônjuge e filho (s) & 10 & 22,2 \\
Idoso e cônjuge & 4 & 8,8 \\
Somente o idoso & 2 & 4,4 \\
\hline Total & 45 & 100 \\
\hline
\end{tabular}

FONTE: Pesquisa de campo 2006. 
Dentre as pessoas que dependem da renda do idoso $35,8 \%$ são filhos, $22,2 \%$ cônjuge e filhos e $28,8 \%$ são outros parentes, como se pode perceber na tabela acima. Verifica-se dessa forma a importância da renda do idoso para as famílias pesquisadas e o perigo da diminuição do benefício recebido através da Previdência Social.

Através das entrevistas dos idosos pôde-se notar que estes se reconhecem no papel de provedores da família. Eles percebem que sua função dentro do núcleo familiar é muito importante e que sua ajuda é fundamental para a sustentabilidade da família e isso lhes pesa, causa preocupação, porém também faz com que se sintam importantes, fundamentais até para o equilíbrio de seus núcleos familiares, o que reforça sua autoestima. Pôde-se constatar principalmente naqueles que além de provedores são cuidadores de netos, filhos, irmãos e até de mães o quanto isto lhes custa em termos de dedicação, abnegação de coisas que gostariam de estar realizando e preocupação em relação a seus dependentes e sua condição de idoso.

Eu ainda ajudo eles, sou o cabeça... tem partes boas e as partes que não são tão boas assim, por exemplo, meu rapaz que está desempregado, gera preocupação (Idoso 11).

Alguns se sentem tolhidos em sua autonomia por serem cuidadores e terem outras pessoas que dependem deles e, desta forma, não poderem realizar tudo o que gostariam de fazer e que agora teriam tempo para fazer, em função de já estarem aposentados, porém, como são os provedores e muitas vezes também os cuidadores, não podem realizar.

Eu me sinto presa, amarrada por causa da mãe. Eu não quero morrer, quero aproveitar a vida bastante ainda, a vida é tão bela, as pessoas é que estão viradas. Agora estou ficando fraca e quase não saio. Os filhos e o marido não querem então eu acabo não saindo quase. Eu gostaria de ir junto com a terceira idade para as águas termais, praia, mas não posso. Meu marido não se interessa mais (Idosa 04).

As falas dos idosos e das idosas demonstram o peso que o fato de ainda exercer a função de "chefe de família" representa para eles e, a responsabilidade que estes sentem por cuidar e sustentar os seus. Aqui "seus" refere-se não apenas a filhos/as, mas também a netos/as, sobrinhos/as, irmãos/ãs. Pelo fato da longevidade ser uma realidade, encontraram-se 
também mães entre os familiares, ou seja, idosos cuidando de idosos, fato que começa a ser mais comum em nossa sociedade.

O Estado possui interesse em que esta relação se mantenha e se fortaleça, pois a solidariedade econômica acaba não só mantendo os idosos independentes, mas também auxiliando os filhos desempregados, ou netos, etc. Fenômeno que se percebe nas famílias em estudo, os idosos em melhor situação econômica graças aos rendimentos de aposentadoria e pensões, sustentando ou auxiliando filhos, netos e outros parentes.

Os filhos dificilmente ajudam porque não podem, mas com gestos um ajuda o outro. Somos família humilde, mas unida. Quando estou ruim, o filho faz o serviço, cuida de mim (Idosa 08).

Constatou-se que a maioria das falas aponta para uma satisfação em relação a seus familiares e, por viverem em família, muitos trazem o sentimento de reciprocidade de estar recebendo atenção por parte dos familiares, carinho e ajuda em troca de auxílio financeiro, como se houvesse uma compensação pela dedicação. Esse sentimento de solidariedade familiar é apontado por Areosa (2008) como um importante instrumento não só para manutenção afetiva, social e psicológica, mas econômica entre familiares.

\section{Considerações finais}

Os dados da pesquisa apontam que o idoso, apesar da idade, mantém a condição de provedor da família, exercida antes de chegar à terceira idade e, isto pode estar associado à dificuldade do jovem se inserir no mercado de trabalho, no aumento do desemprego, falta de políticas de inclusão, o que acaba sendo traduzido como melhores condições para o idoso. Porém, deve-se atentar para o fato de que esta não é uma regalia nem uma benesse, senão que o idoso tem mais uma "carga", um peso para suportar na sua velhice, o fato de continuar tendo familiares que dependem da sua renda.

\section{PROVIDERS ELDERLY: THE IMPORTANCE OF RESOURCES TORETIREMENT THE BRAZILIAN FAMILIES}

\footnotetext{
Abstract

This paper presents how snip the "old provider" that through the benefit of social foresight (retirement and pension) is the maintainer of your family, the "boss". In this investigation we interviewed 34 people with over 60 years old, core family providers with the resource of your retirement and / or pension. It was found in the sample 59\% of retirees and 57,3\% from these report that live only with the retirement resources, $22,4 \%$ of the surveyed lives from the Barbarói, Santa Cruz do Sul, n.45, p.<173-184>, jul./dez. 2015
} 
pension and $14,2 \%$ link the rents as a way of keeping. The elderly recognize it self as providers of their core family and, this is causing concern and restriction of freedom, but also they feel important and valued.

Keywords: Elderly provider. Retirement. Family income.

\section{PROVEEDORES ANCIANOS: LA IMPORTANCIA DE LOS FONDOS DEJUBILACIÓN PARA LAS FAMILIAS BRASILEÑAS}

\section{Resumen}

En este trabajo se lleva a cabo el corte de edad \&quot;anciano proveedor\&quot; que utilizade los beneficios de la seguridad social ( jubilaciones y pensiones ) es elencargado de mantener a su familia , el \&quot;jefe\&quot;. En esta investigación seentrevistó a 34 personas con más de 60 años, los proveedores de la familianuclear con la capacidad de jubilación y / o pensión. Se encontró en la muestra59 \% de los pensionistas y el 57,3\% de ellos informan experimentar sólo de losfondos de retiro, el 22,4\% de los encuestados viven de pensiones y el 14,2 \%dijo rentas con el fin de mantener. Los ancianos son reconocidos comoproveedores de sus hogares, y esto les está causando preocupación y larestricción de la libertad, sino también sentir importante y valorado.

Palabras- clave: Anciano proveedor. Jubilación. Renta familiar.

\section{Referências}

ANDERSON, Maria Inez Padula. SAÚDE E CONDIÇÕES DE VIDA DO IDOSO NO BRASIL. Textos Envelhecimento [online]. vol.1, n.1, p. 7-22, 1998. ISSN 1517-5928.

AREOSA, Silvia Virginia Coutinho. Envelhecimento, contexto social e relações familiares: o idoso, de assistido a provedor da família. Tese de Doutorado. Programa de Pós Graduação em Serviço Social da PUCRS, 2008.

BARDIN, Laurence. Análise de conteúdo. Lisboa: Edições 70, 2004.

CAMARANO, Ana Amélia. $O$ idoso brasileiro no mercado de trabalho. Rio de Janeiro: IPEA, 2001.

CAMARANO, Ana Amélia (org.). Muito Além dos 60: os novos idosos brasileiros. Rio de Janeiro: IPEA, 1999.

CAMARANO, Ana A.; PASINATO, Maria T. Envelhecimento, condições de vida e política previdenciária. Como ficam as mulheres? Rio de Janeiro: IPEA, 2002.

FRANÇA, L. H. de F. P.; VAUGHAN, G. Ganhos e perdas: atitudes dos executivos brasileiros e neozelandeses frente à aposentadoria. Psicol. estud., 13(2), p.207-216, 2008. Recuperado em 16 de abril, 2011, da SciELO (Scientific Electronic Library On line): www.scielo.br 
IBGE - Pesquisa nacional por amostra de domicílio, 2006. Documentação dos microdados da amostra. Rio de Janeiro: IBGE, 2007. 54p. 1 CD-ROM.

IBGE - Instituto Brasileiro de Geografia e Estatística. Síntese de Indicadores Sociais. Uma análise das condições de vida. Rio de Janeiro: Estudos e pesquisas, Informação demográfica e socioeconômica, n.21, 2007.

KRELING, N. H. Os idosos e as novas evidências nas relações com a família e com o trabalho. In: WILTGEN, R. S.; GARCIA, L. S. (Coord.). Transformações do mercado de trabalho metropolitano. Porto Alegre: FEE, FGTAS/SINE-RS, DIEESE, SEADE-SP, PMPA, p. 97-120, 2002.

LIMA, Lara Carvalho Vilela de. ; BUENO, Cléria Maria Lobo Bittar. Envelhecimento e Gênero: a Vulnerabilidade de Idosas no Brasil. Revista Saúde e Pesquisa, v. 2. n.2, p. 273280, 2009.

MORAGAS, Ricardo Moragas. Gerontología Social: Envejecimiento y calidad de vida. Barcelona: Ed.Herder, 1995.

NERI, A.L; DEBERT, G.G. Velhice e Sociedade. $2^{\mathrm{a} e d . ~ C a m p i n a s, ~ S P: ~ P a p i r u s, ~} 2004$.

TUR, Carmen Triadó; OLIVARES, Maria José Osuna.Las relaciones abuelos-nietos.In: HERNANDIS, Sacramento Pinazo; MARTINEZ, Mariano Sánchez(orgs.). Gerontología: Actualización, innovación y propuestas. Madrid: PearsonEducación S.A.,2005.p.259-288.

ZIMERMAN, Guite L. Velhice: aspectos biopsicossociais. Porto Alegre: Artes Médicas Sul, 2000.

Data de recebimento: $13 / 01 / 15$

Data de aceite: $28 / 07 / 16$

\section{Sobre a autora:}

Silvia Virginia Coutinho Areosa é Professora de Psicologia desde 1990, na UNISC desde 1996. Doutorado em Serviço Social na PUCRS. Doutorado sanduiche na Universidade de Barcelona (ES). Endereço eletrônico: sareosa@unisc.br 